\title{
Agent-based Modeling of Consumer Purchase Decision-making Process considering Quality of Web
}

\author{
Nan Zhang \\ Harbin University of Commerce \\ Harbin, China, 150028
}

\begin{abstract}
The problem of consumer purchase decisionmaking has been of great interest of researchers. The traditional model of mathematics and statistics is a static process. However, consumer purchase decision-making includes many fields, which is a social process of complexity. So, this paper builds an agent-based model of consumer purchase decision-making. Moreover, an agent-based frame structure of the consumer's purchasing behaviors considering quality of website is proposed. The frame structure is a motivation function that involves price of commodity, quality of commodity, and quality of web. In the future, the agentbased model need to be executed in the simulation platform and validated systematically.
\end{abstract}

Keywords-agent-based modeling; consumer purchase decision; motivation function; quality of website omponent

\section{INTRODUCTION}

As the rapid development of e-commerce, online shopping has become the main way of shopping in society. According to the China Internet Network Information Center reported in June 2016, there are 448 million consumers by online shopping, and $8.3 \%$ growth rate [1]. Among, 401 million consumers used cell phone online shopping. Moreover, China's online shopping market research report in 2015 showed that the total numbers of online shopping transaction are 25.6 billion times [1].

It is well known that price and quality are important factors in purchasing behavior, where explain the difference in purchasing behavior the similar competitive products in the market. Therefore, many commodities have attributes of high quality and low price. With the development of ecommerce, consumers purchase decision making depend on some other variables except for price and quality of commodities. Researchers have confirmed that quality of website influence online shopping of the consumer behavior [2]. Quality of website is not a unity concept, but is a multidimensional concept, which includes information quality, system quality and server quality [3-8]

Traditionally, the method of mathematics and statistics are used to build the models of consumers purchase decision making. So, the model is a static process. However, consumers purchase decision making include research in the field of personality, psychology, sociology, marketing, which is a social problem of complexity. Therefore, a newly agent techniques to model consumers' decision making process. Agent-based simulation is a bottom-up technique that has offered a robust tool to cope with the complexities in a complex system. Some researchers have used the method of agents-based to simulate consumers' behavior. Zhao et al [9] described green purchase behavior of bounded rational consumers based on computational experiments. Jin Chun et al [10] proposed an agent-based modeling and simulation method to build customer behavior and personalized recommendation. Jin Chun et al [11] proposed an agentbased modeling and simulation method on the consumer's purchasing behaviors under the website promotions. Schenk et al [12] presented the particulars of an agent-based micro model for grocery shopping, based on an individual population and store data gathered in northern Sweden. Roozmand et al [13] proposed an agent-based conceptual and computational model of consumer decision-making based on culture, personality and human needs.

A current view from of research perspective, considering trust of website in agent-based modeling of consumer decision making process is limited. This paper developed an agent-based consumer purchased decision-making model based on the motivation function and quality of website. The rest of this paper is organized as follows. In Section 2, the motivation function of consumer purchased decision-making is presented. Section 3 will builds an agent-based consumer purchased decision-making model. Finally, conclusions are given in Section 4.

\section{THE MOTIVATION FUNCTION OF CONSUMER PURCHASED DECISION-MAKING}

Consumers' purchase decision-making processes are consumers to satisfy his or family life need. Purchase decision-making is a cognitive process, which are used to describe by the motivation function. Just as mentioned above, in this paper, the motivation function is presented as price of commodity, quality of commodity and quality of web.

\section{A. Price of Commodity}

The motivation function of price of commodity is as shown:

$$
U_{p}=P_{\mathrm{i}} * P S_{\mathrm{i}}
$$

Where $P_{i}$ is the price of commodity $i, P S_{i}$ is the price sensitivity parameter of commodity $i$. 
According to the Kim's research, $P S_{i}$ may be expressed to difference value that real price of commodity $i$ and the expected price of commodity $i$.

That is to say

$$
P S_{\mathrm{i}}=-\alpha^{P_{\mathrm{i}}-P_{\alpha}}+k
$$

Where $\alpha$ is parameter, $P_{e}$ is the expected price of commodity $i, k$ is a constant parameter.

In real, $P_{\theta}$ is a difficult to compute, and $P_{\theta}$ is usually to show that the average price of the commodity $i$. As shown in Eq. (3)

$$
P_{e}=P_{\text {ave }}=\frac{1}{N} \sum_{i=1}^{N} P_{i}
$$

Where $P_{\text {ave }}$ is the average price of the commodity, $P_{\mathrm{i}}$ is the price of the commodity $i$, and $N$ is number of the commodity $i$.

According the Eq. (2) and Eq.(3), $U_{p}$ is

$$
U_{p}=P_{i} *\left(-\alpha^{P_{i}-\frac{1}{N} \sum_{i=1}^{N} P_{i}}+k\right)
$$

\section{B. Quality of Commodity}

The motivation function of quality of commodity $i$ is as shown:

$$
U_{q}=Q_{\mathrm{i}} * Q S_{i}
$$

Where $Q_{i}$ is the quality of commodity $i, Q S_{i}$ is the quality sensitivity parameter of commodity $i$.

In general, there are several different attributes in commodity, such as performance endurance life, reliability, safety, economical efficiency and so on. Therefore, the quality of commodity is a multidimensional variable. Here, we assume that there are $\mathrm{n}$ attributes in commodity $i$, then the $Q_{\text {i }}$ can be as shown

$$
Q_{i}=\sum_{i=1}^{N} W_{i} Q_{i j}
$$

Where $Q_{\mathrm{i} j}$ is the quality $\mathrm{j}$ of commodity $i$ and $W_{\mathrm{i}}$ is weight of $Q_{i j}$.

Patel and Schlijper [14] indicated that the quality sensitivity parameter of commodity lied on the different value between the real quality of commodity and the expected quality of commodity. So the Eq. (7) is

$$
Q S_{\mathrm{i}}=\beta^{\left|Q_{\mathrm{i}}-Q_{\mathrm{a}}\right|}+l
$$

Where $\beta$ is a parameter, and $l$ is a constant parameter, and $Q_{e}$ is the expected quality of commodity $i$. Here, $Q_{e}$ is computed by the average quality of the commodity $i$, and the formula is

$$
Q_{e}=Q_{a v e}=\frac{1}{N} \sum_{i=1}^{N} Q_{i}
$$

Where $Q_{\text {ave }}$ is the average quality of the commodity.

According the Eq. (7) and Eq. (8), $U_{q}$ is

$$
U_{q}=\sum_{j=1}^{N} W_{i} Q_{i j} * \beta^{\left|Q_{i}-\frac{1}{N} \sum_{i=1}^{N} Q_{i}\right|}+l
$$

\section{Quality of Website}

Quality of website is multi-dimensional variable, which involves information quality, system quality and server quality. Here, quality of web as shown:

$$
Q w_{i}=\sum_{j=1}^{W} W_{j} Q_{j}
$$

Where $Q_{j}$ is the quality of attribute $j$ and $W_{i}$ is weight of attribute $j$.

Based on mentioned quality of commodity, the motivation function of quality of website is

$$
U_{q w}=\sum_{j=1}^{W} W_{j} Q_{j} * \gamma^{\left|Q_{j}-\frac{1}{N} \Sigma_{j=1}^{N} Q_{j}\right|}+h
$$

Where $\gamma$ is a parameter, and $h$ is a constant parameter.

\section{AGENT-BASED MODEL}

In agent-based model, agent is defined as smart entity that includes autonomy, social ability, responsiveness and active ability [13]. Agents interact with and influence each other, learn from their experiences, and adapt their behaviors so they are better suited to their environments. By modeling these agents individually, the full effects of the diversity that exists among agents with respect to their attributes and behaviors can be observed as they give rise to the dynamic behavior of the system as a whole $[15,16]$. The basic content of agent-based model is agent, intelligent and interaction. In agent-based model, agent is a basic abstract unit of the real system. Agents are given the intelligent and set the interaction between agents. Agent-based model is a kind method of bottom-up modeling. First Agent-based model establishes the agent unit of the real system. Second, these agent units were assembled using system structure. Finally, the real system was built. The multi-agent system is defined that there are many agents. In general, the multi-agent system includes three layers: agent, property model layer, and multi-agent system layer.

Compared with the traditional method of mathematics and statistics, agent-based simulation has many advantages:

- In the traditional method of mathematics and statistics, the model of consumer purchased decision-making is static process. In agent-based model, simulation is used to build the behavior and action of consumer purchased decision-making, which is dynamic process.

- Using subjects of data mining, equilibrium-based mathematics and statistics, consumer behavior, and social psychology, the cost of the traditional model is very expensive. These problems are resolved by agent-based model.

- In agent-based model, agents are able to control itself environments. And agent-based model is a flexible method.

\section{CONCLUSION}

Agent-based models have recently been built by some researchers to simulate the reality society. However, agent- 
based modeling and simulation method to build customer behavior is limited. Moreover, research confirms that price of commodity, quality of commodity and quality of web influence the consumer behavior. So, this paper presented agent-based frame structure of consumer purchase decisionmaking considering price, quality of commodity, and quality of website. In this paper, we just proposed a frame structure, but not simulate the real consumer behavior. In further, we will program the motivation function with Repast.

\section{ACKNOWLEDGMENT}

This paper is supported by the Heilongjiang Postdoctoral Grant No.LBH-Z15115, and the Harbin University of Commerce under Grant No.15RW21.

\section{REFERENCES}

[1] Statistical Report on China Internet Development [R]. China Internet Network Information Center, 2016.

[2] Dong Xiang-dong. Research on Purchase Decision of Young Consumers based on Function Price and Brand Reference Case Study of Mobile Phones. Journal of Zhejiang Sci-Tech University (Social Sciences), 34(6), 2015, 489-495.

[3] Song Xue-ting. Research on the Relationship of B2C E-commerce Websites' Overall Quality, Customer Satisfaction and Purchase Intention [M]. 2013.

[4] Li Cunchao. Research on the Influencing Mechanism of Service Quality of E-commerce Platform on Brand Equity [M]. 2014

[5] Sun Xiao-dong. Tian Peng. Zhao Li. Consumer Heterogeneity and Pricing Strategies: A Quality-Price Competition Model [J]. Journal of System and Management, 22 (3), 2013.

[6] Zou Yue. The Impact of B2C Web site Quality on Customer Attitude Based on TAM Theory Taking Large-scale Comprehensive Web sites as Examples[M].2013.

[7] ChenYi-bing. The Impact of E-commerce Website Quality on Customers' Online Trust [M]. 2010

[8] Yang Zhao-jun, Cao Li-sha, Zhang Yali. Formative Website Quality and Purchase Intention-Cross-validation Analysis of Multinational and Domestic E-commerce Companies [J]. Journal of Modern Information. 35(5), 2015. 41-62

[9] Zhao Ai-wu, Du Jian-guo, Guan Hong-jun. Green purchase behavior of bounded rational consumers based on computational experiments [J]. Systems Engineering-Theory and Practice. 35(1), 2015. 95-102

[10] Jin Chun, Zhang Yi-ping. Agent-based simulation model of customer behavior and personalized recommendation [J]. Systems EngineeringTheory and Practice. 33(2), 2013. 463-472

[11] Jin Chun, Dong Qiu, Lu Miao. Agent-based simulation for consumer behavior under website promotion [J]. Systems Engineering-Theory and Practice. 34(4), 2014. 845-853.

[12] Schenk T A , Lo " ffler G, Rauh J. Agent-based simulation of consumer behavior in grocery shopping on a regional level [J]. Journal of Business Research, 2007, 60(8): 894-903.

[13] Roozmand O, Nasser G A, Hofstede G J, et al. Agent-based modeling of consumer decision making process based on power distance and personality[J]. Knowledge-Based Systems, 2011, 24: 1075-1095.

[14] Patel S. Schlijper A. Model of consumer behavior [R]. Report on ESGI 2004, 2004.

[15] Ahn H J. Evaluating customer aid functions of online stores with agent-based models of customer behavior and evolution strategy [J]. Information Sciences, 180(9), 2010, 1555-1570.

[16] Zhang T. Zhang D. Agent-based simulation of consumer purchase decision-making and the decoy effect $[\mathrm{J}]$. Journal of Business Research, 60(8), 2007, 912-922. 